\title{
Interpreters' Identities: An Exploratory Study of Vietnamese Interpreters in Vietnam
}

\author{
Dr. Elisabeth Le, University of Alberta \\ Dr. Nathan Ménard, University of Montreal \\ Dr. Nguyen Van Nhan, University of Ha Noi
}

Throughout history, interpreters have suffered from the suspicion attached to their perceived multiple cultural belongings (Kaufman): how could they possibly be faithful to their cultural group and serve their master dutifully when they are demonstrating their belonging to another culture (i.e. in translating into the language of that other culture)? Paradoxically, the knowledge of several languages may have been prestigious, but only if put to the benefit of oneself and not of others. Thus, it is the position of intermediary (and not the knowledge of different languages) that is the essential cause of this mistrust.

Considering our necessarily limited knowledge of foreign languages and the multiplication of contacts between cultures, interpreters have always been necessary; and despite the "international" status that one or two languages may enjoy or develop, this need is not likely to disappear. Unfortunately, the uneasiness towards interpreters remains; one way to dispel the suspicion brought by their intermediary position is for interpreters to "disappear". To make sure that they do not "betray their masters", interpreters have been instructed to become "invisible". To see, or check, how this is done, many interpreting studies have focused on the message transmitted by interpreters, i.e. what and how interpreters translate, what they add or delete and how.

When speaking with interpreters, it is amazing to hear how a number of them in the same breath proclaim their allegiance to "invisibility" (as they have been duly instructed) and describe various ways in which they are visible in their professional practice. In academia, the progressive abandon of Shannon and Weaver's mathematical sender-receiver model in favour of socio-cultural models of communication has finally brought researchers' attention to the interpreter as a "complete human being" (i.e. a rational and emotional being with his/her specific socio-cultural background and living and interacting in a specific society). A number of studies have followed that have dispelled the myth of interpreters' invisibility (Angelelli (b); Bolden; Metzger; Roy; Wadensjö). Not 
only can interpreters not be invisible, they might very well need to be visible. Thus the question that should be raised is the type(s) and the extent of visibility interpreters may assume, and moreover may want to assume, in a given situation. For interpreters to be able to decide for themselves how to answer this question, they must first be given the opportunity to think about the situation. This paper purports to show why it is important to focus on interpreters' sociocultural and professional identities during their training.

To tackle this question, a brief review of literature is first helpful (1). Then, the importance of the issue is illustrated with a concrete case, Vietnam (2). It is followed by the presentation of the exploratory study: methodology (3) and results (4). The conclusion (5) puts forward the point that recognizing interpreters' visibility is only a first step in giving them the place they deserve.

\section{Literature review}

To give a general idea of why and how interpreters might be visible or not, this brief literature review deals with the types of situations in which interpreters operate, the types of translation they practise, and the types of roles they may choose to enact.

In her typology of interpreter-mediated events, Alexieva distinguishes between a number of parameters that belong to two large groups: mode of delivery and elements of the communicative situation. The mode of delivery can take four different forms. Simultaneous interpreting, common in international conferences, corresponds to a non-stop delivery achieved with the help of ancillary equipment such as microphones and headphones. It is characterized by a spatial distance between the primary participants and the interpreters who might not be in the same room. Chuchotage (i.e. whispering) is also simultaneous but it implies physical proximity between interpreters and addressees, as these must be able to hear directly what interpreters tell them. Consecutive interpreting is a direct face-to-face communication that differs from chuchotage first by its timing and second by its eventual use of ancillary equipment. In this case, the physical distance between participants and interpreters is greater than in chuchotage, but lesser than in simultaneous interpreting. Finally, liaison interpreting takes place in situations of spontaneous and improvised oral exchanges; it is consecutive, direct and not mediated by ancillary equipment. The elements of communication include: participants, topic, text type and text building strategies, spatial and temporal constraints, and goal of the event. Each of these elements presents 
different facets that are located along continuums of values and result in a "universal" vs. "culture-specific" situation:

- "distance" vs. "proximity" (between speaker, addressee, and interpreter),

- "non-involvement" vs. "involvement" (of the speaker as text entity);

- "equality/solidarity" vs. "non-equality/power" (related to status, role and gender of the speaker's addressee, as well as to the interpreter);

- "formal setting" vs. "informal setting" (related to number of participants, degree of privacy, and distance from home country);

- "literacy" vs. "orality";

- "cooperativeness/directness" vs. "non-cooperativeness/indirectness" (relevant to negotiation strategies);

- "shared goals" vs. "conflicting goals".

The interpreter-mediated events in which interpreters are most "present" are those for which the mode of delivery implies a direct and close contact with the participants (i.e. chuchotage, liaison interpreting, and consecutive interpreting when it does not involve the use of ancillary equipment), and in which the elements of communication tend to shape a more culture-specific situation.

A taxonomy of types of translation (i.e. renditions) is provided by Wadensjö in her study on interpretation as interaction. It is based on the assumption that interpreters would try to stay as close as possible to the original utterances. The comparison between authentic interpreted-mediated interactions and original utterances reveals that interpreters engage in various types of renditions:

- Close rendition (same amount of explicitly expressed propositional content rendered in the same style);

- Expanded rendition (including more explicitly expressed propositional content);

- Reduced rendition (with less explicitly expressed propositional content);

- Substituted rendition (combination of expanded and reduced renditions);

- Summarized rendition (corresponding to two or more originals provided by one or more interlocutors);

- Two-part or multi-part rendition (rendering of one original in two or more parts, the parts being separated by another original whose propositional content is not reflected in the rendition);

- Non-rendition (interpreter's text, on the basis of the interpreter's initiative, that does not correspond to an original);

- Zero-rendition (originals are left untranslated in part or whole).

It appears thus that except in cases of close renditions, interpreters are always "visible". 
Finally, a very useful taxonomy of interpreters' role is given by Jalbert (qtd. in Leanza 13-14):

- Translator: The interpreter minimizes her presence as much as possible. In this role she simply facilitates the communication process, not interfering with what the speaker says.

- Cultural Informant: The interpreter helps the healthcare provider to better understand the patient. In this role the interpreter uses her knowledge of cultural norms and values.

- Culture Broker or Cultural Mediator: The interpreter is a cultural informant but also a negotiator between two conflicting value systems or symbolic universes. In this role, the Culture Broker needs to enlarge, provide explanations or synthesize healthcare providers' and patients' utterances to help both parties arrive at a meaningful shared model (of care, of behaviour etc.).

- Advocate: In a value-conflict situation, the interpreter may choose to defend the patient against the institution.

- Bilingual Professional: The interpreter becomes the healthcare professional. She leads the interview in the patient's language and then reports to the healthcare provider. She can do this because of prior training in health care or, in a more limited way, because of her knowledge of institutional practices and routines.

While Jalbert's (and Leanza's) work has borne on healthcare situations, there is $a$ priori no reason why it could not apply mutatis mutandis to other types of situations. According to this taxonomy, the interpreter is "visible" in each role except for the "translator"'s one.

In sum, it appears that the taxonomies of interpreter-mediated events, interpreters' renditions and interpreters' roles point to interpreters' visibility and may make their "invisibility" the exception rather than the norm. In practice, while the great majority, if not all, translators might say that they are first "translators", and in that role try to give "close renditions", they also recognise that their work goes beyond that. Thus, instead of starting with the assumption that interpreters are invisible, it would seem much wiser to acknowledge their presence and active participation in the interactions, and therefore to put interpreters as "complete human beings" at the centre of interpreting studies and training. 
The importance of interpreters is particularly felt in highly charged human interactions such as healthcare, court settings, and social and immigration services. It is thus no wonder that many recent studies on the role and place of interpreters relate to "community interpreters" who work in these types of situations (Angelelli (a), Brunette et al. and Roberts et al.). Without denying the social value of such studies in any way, there is however another domain where interpreting might carry an even greater significance: international and transnational relations. Indeed, these types of relations not only involve individuals who interact with each other, but also have consequences on the socio-cultural and economic development of nations, especially when developing countries are concerned. The rest of this paper relates to an exploratory study of Vietnamese interpreters in Vietnam.

\section{Importance of interpreters in Vietnam}

The importance of interpreters in any given country is partially dependent on that country's level of integration on the international stage. That itself results from historico-political and economical factors. In 1975, after several decades of war, Vietnam achieved its reunification. In 1986, it adopted its Doi Moi policy with a focus on economic reform. The $10^{\text {th }}$ National Congress of the Communist Party in 2006 decided for external affairs to: ${ }^{1}$

- First, [...] promote new developments in the cooperative relations with a view to bringing substance, stability and sustainability to cooperation and creating mutual trust.

- Second, actively promote deeper and more comprehensive international economic integration [...]

On 11 January 2007, Vietnam gained full membership in the World Trade Organization. From 2000 to 2007, Vietnam's GDP increased rapidly (in billion US $\$$ : from 31.173 to 71.216 - World Bank) as well as its level of exports of goods and services (from $55 \%$ to $76 \%$ of GDP - World Bank). As for foreign direct investment, it grew by 56\% from 2000 to 2006 (in billion US \$: 1.298 in 2000 to 2.315 in 2006 - World Bank), and it is expected to benefit greatly from the development of international economic integration that WTO membership facilitates. This type of economic development takes place in a network of intercultural communication whose efficiency depends in great part on interpreters. Whatever their domain of work (e.g. diplomacy, cooperation, joint-

${ }^{1}$ Press Conference on Foreign Policy and International Economic Integration. 7 November 2006. Government website of the Socialist Republic of Vietnam. 17 September 2008. 
ventures, tourism), Vietnamese interpreters contribute to a better understanding between individuals of different cultures and to the development of their country in general.

As of 12 December 2004, the 11 leading countries investing in Vietnam were (in decreasing order of importance of registered capital): Singapore, Taiwan, Japan, South Korea, Hong Kong, British Virgin Islands, France, The Netherlands, Thailand, Malaysia, and the USA. ${ }^{2}$ In their mediation, the interpreters' task is particularly complex towards Western countries: to help attract and retain foreign investments, they are supposed to facilitate the activities of individual members of an individualistic (e.g. French / American) out-group within, and as representatives of, their own collectivistic (Vietnamese) in-group. Added to this difficulty is the fact that the out-group might represent a country with whom Vietnam has been at war not that long ago (e.g. France, USA). Vietnamese interpreters are thus at the hub of a complex intercultural and power relations network. Interpreters are at the centre of interpreter-mediated communication and their identities are a source of meaning for their interactions (Pym). When these interactions take place in a context of socio-cultural and economic inequalities, their identities become even more crucial (Navarro-Montesdeoca). Unfortunately, while a few studies have been conducted on the negotiation (Rudvin) and impact (Pöllabauer) of interpreters' identities, none has focused on their cultural identities from a systematic ethnographic perspective.

\section{Methodology}

In an exploratory study conducted in Hanoi in May 2008, seven Vietnamese interpreters answered questions on their professional and cultural identities in a semi-directed interview. The concept of identity is defined here in accordance with the Communication Theory of Identity (Hecht, Jackson and Ribeau). In this theory, identity comprises four interpenetrated layers: the personal layer (i.e. the individual as locus of identity), the enactment layer (i.e. identity is enacted in communication through messages), the relational layer (i.e. relationship is the locus of identity), and the communal layer (i.e. a group is a place where identity exists). Major questions relating to identity might thus be formulated as follows: how do interpreters define their roles (personal layer); how do interpreters interact with interlocutors A and B (enactment and relational layers); and, how do interpreters define themselves vis-à-vis the cultures of interlocutor $\mathrm{A}$ and

${ }^{2}$ Socialist Republic of Vietnam. Ministry of Foreign Affairs. "Foreign investment into Vietnam." 17 September 2004. 
interlocutor B (communal layer)? In this perspective, the questionnaire used in the semi-directed interviews (see appendix A) focused on interactions in interpreter-mediated events as seen from the interpreters' perspective: how they perceived the interactants' feelings and actions, and how they themselves felt and behaved during satisfactory as well as unsatisfactory tasks. "Satisfaction" was approached in terms of appropriateness (socio-cultural dimension), efficiency (practical dimension), pleasantness (affective dimension), and cultural knowledge (cognitive dimension). Other questions related to the interpreters' roles and cultural belongings. ${ }^{3}$

The interviews took place in French or English (depending on the interpreters' working language) and lasted from 75 minutes to 105 minutes. All interviewees (four males and three females) are experienced interpreters working for foreign public or private institutions or the Vietnamese government ${ }^{4}$. They all hold university degrees and six received professional training in interpreting (four of them abroad - two others also studied abroad in a related domain). Their age ranges from early 30s to early 50s. Thus, the youngest ones were born around the end of the American war ${ }^{5}$ when Vietnam was reunified, and the oldest ones were born around the end of the French colonial war. The circle of high-level interpreters being relatively limited in Hanoi, it has been deemed necessary to go beyond the usual measures of confidentiality required by university research ethics. Thus, all excerpts from the interviews are given in English only, and they were all edited to guarantee that the interviews' language (i.e. the interpreters' working language) cannot be guessed. It may seem paradoxical that in a qualitative study on interpreters' identities, basic methodological standards of participants' and data presentation (i.e. personal information on each participant, original language, no editing of any sort) are deliberately ignored. However, one must note that this affects only the presentation of data in this paper, not the analysis itself as it was done on the basis of the complete original transcriptions of the interviews.

\section{Results}

\footnotetext{
${ }^{3}$ As defined by Jalbert; see above; see also question 10 of the questionnaire in Appendix A.

${ }^{4}$ In Vietnam, it is uncommon for interpreters to do interpretation on a full-time basis.

${ }^{5}$ Called "Vietnam war" in the USA.
} 
The great majority of interpreter-mediated events described in the interviews involved chuchotage, liaison interpreting, or consecutive interpreting (with no use of ancillary equipment). The content of the interviews is presented around four major issues: the centrality of the interpreter as a human being (4.1), the types of rendition provided by the interpreters (4.2), the interpreters' professional roles (4.3), and their self-perceived cultural belongings (4.4).

\subsection{Centrality of the interpreter as a human being}

Apart from the special skills and knowledge involved in the interpretation process, the person of the interpreter appeared central as illustrated in the following excerpts taken from the interviews. In (1), the interviewee underlines the interpreters' emotional hardship when interlocutors do not respect them and treat them as a "translation machine". The interpreters' emotional / psychological well-being matters as it necessarily has an impact on the approach interpreters adopt in their work towards the interlocutors $(2,3)$. In fact, it is likely to be the key element in the most satisfactory interpreter-mediated communicative events $(3,4)$.

(1) First, the $X$ side must completely trust the [Vietnamese] interpreter, and then the Vietnamese side must also trust the interpreter, and respect him, especially respect him, because when the Vietnamese side does not, it is catastrophic for the interpreter. When the interpreter does not understand something and asks a question, if there is no respect from the Vietnamese side, [then they say:] "you translate, that's it, I told you [to translate]". It is very hard. (IEE1)

(2) Could we try to explore this idea a bit further? You are given an interpretation task. Which criteria are you taking into account to decide which supplementary explanations you are going to give, when you are going to be more concise, which attitude towards each partner you are going to adopt?

First, I ask myself questions: how, what, where; that is, all the traditional questions about the situation in general, the work to be done and its context. Then, I ask myself, what about this participant, what do I know about him, is it enough or not, does he represent the majority of the participants or not. Later during the meeting, I observe the participants' reactions. However, the most important moment for me is the pause; there is always a pause; during the pause, they can relax, but for me, it is a "working pause" because at that time I can speak with them, I ask them 
questions: do you understand [the translations], how difficult is it to follow [the translation], what about the speed? These questions may be simple but they are very useful to me. (IEE3)

(3) That day, the artist from X came and gave his class, a new class. He had a special, an extraordinary pleasure in giving this class, nothing like what he was doing before. Right away, I captured his pleasure in giving his class, in trying to explain things; as if I had forgotten everything else, I interpreted for the students; I tried to do my best, with a lot of pleasure. It was a very special moment in my life. Until now, I still do not understand how I could do this. [...]

[An older man present in the audience told me:] I am the professor of these students. I gave them the same class; I understand the content of this class perfectly well. But you, you are an interpreter; I suppose that you don't know anything about this content; it is your first time, the first time you hear about it. How were you able to transmit it? As a professor, I felt, I understand how well you were able to translate the essential; you translated very well what the professor from $X$ said. [...]

It is, I would say it was a unique moment in my life, because afterwards, I tried to do the same thing, in other circumstances, but it is not easy to give the same pleasure, it is not easy to have the same pleasure. (IEE3)

(4) During the discussions, when I think that one party or the other is lagging behind, is waiting, then I explain, including to the $X$ party. I explain and the $X$ party understands, it takes a different attitude towards the Vietnamese party and the Vietnamese party understands why I behaved this way. Without this respect, this mutual trust, it is impossible to work. (IEE1)

\subsection{Renditions}

As seen above, the interpreters' psychological / emotional well-being has an impact on the manner they approach and accomplish their work. The question of trust is of paramount importance (5).

(5) I am trusted when before going to a meeting I am told, look this is what we want, this is what we want to say. This is good for me to understand the picture; when I understand, I know the background better, I can interpret better. (IEE2) 
The interviews revealed that interpreters engage in expanded, substituted, summarized, zero- and non-renditions alongside close rendition. In the same assignment, they combine different types of rendition.

In expanded renditions, they add by explaining, by supplying information one of the interlocutors assumes to be shared knowledge (6).

(6) We give preliminary explanations before asking these questions [from the Vietnamese side to the $X$ side]. Sir, the Vietnamese, the Vietnamese participants have questions for you, but they are somewhat personal questions. It is a Vietnamese custom to ask these questions because in Vietnamese, the system of address is very complicated, and we need to know people's age in order to know how to address them. For example, if you are older, then I need to use a different form of address. (IEE5)

In substituted renditions, they adapt the original utterance most often for issues of politeness $(7,8,9,10)$, sometimes at the demand of the interlocutor $(8)$.

(7) It is the interpreter's task to evaluate the situation and eventually to adapt the [formulation of] propositions so that the Vietnamese party understands and does not take these propositions as orders. (IEE1)

(8) For example, they [foreigners] say: "OK, I say this and you adapt it so that it is appropriate for Vietnamese people". In those cases, we [interpreters] are really happy. In any case, this is the work of interpreters. (IEE1)

(9) It [the foreigner's words] is like questionning. It is like an interrogation, very, maybe sometimes, rude, abrupt, not a nice way of talking. Maybe he expresses his own feelings or he expresses his voters' feelings. [...] I softened it [what he said]. For example, he says, "is that true?" Then I can add one or two words, to ask whether it is true [change of intonation]; thus, I softened it a little bit and maybe I made it easier for the Vietnamese to hear. (IEE2)

(10) He [foreigner] said: "my country pays for your training; thus, don't act stupid!" This was really shocking for the interpreters because it hurts our national feelings but we still have to translate. Thus, we need to 
change the formulation, to be less arrogant than the $X$ partner so that the message can pass, so as not to offend the Vietnamese people who were there. (IEE5)

In summarized renditions, they adapt the propositional content to the interlocutors' level of interest and/or knowledge as they perceive it (11).

(11) Some of the participants are experts in their domain; they don't need the details, but only the core of the message, what is essential. As they don't have much time, it is better to skip the details and give them only the essential. If they need more, they will ask you questions. (IEE3)

In zero-renditions, they omit parts of the original utterance to lessen risks of communication break-down $(12,13)$.

(12) The director of the Vietnamese institute said : no, impossible, we have other things to do. I did not translate. I did not translate, because I understood right away that he misunderstood the intent of the experts from $X$. The experts from $X$, they are direct, very direct, and it is true that in their domain, without data, one can do nothing. But the Vietnamese director, he understood that it [i.e. giving data within a very short deadline] was a condition for the three bursaries, and he thought it was not worth it. He was a bit upset that they would want to impose a condition. [...] If I had translated, I would have put the experts from X in a very difficult situation [...]. Nobody could afford to break up the relationship. The Vietnamese side and the French side did not want it. The goal of their mission was to develop the relationship. Thus, I did not translate. (IEE1)

(13) So, when you translate for one party and you find that this party is wrong, is really wrong, what do you do?

I still translate, interpret it.

And you do not add anything.

As a message, no.

Even when you think that something is really wrong and you think that it's going to lead to a bad outcome. Do you still translate?

Then I don't translate. [...] Then I would go back to the X side as always to make it clear before translating. 
Are you saying that when the $X$ side says something that you think is wrong and would lead to a bad outcome, you go back to them [X side] and explain them the possible outcome before translating?

Yes, yes. (IEE2)

In non-renditions, they engage in an active search for solution by giving explanations, advice (14, 15); sometimes, they even answer in place of the interlocutor (16).

(14) When a partner is wrong, really wrong, then we try to explain. We explain first to the other partners so that they understand and be tolerant, so they do not react right away negatively. We want to give them the possibility to choose, to choose the appropriate strategy. As for the partner who is wrong, we consider her/him later. (IEE1)

(15) If I have some advice to give, I give them after the translation, or when it is necessary, I say, let's stop, let's stop here for a moment, and I tell him/her something. But all of this, it is done apart from the translation. (IEE3)

(16) During the training sessions, we have a tendency to answer [the Vietnamese participants' questions to the $X$ trainer] because we understand the $X$ language and thus we understand the $X$ trainer well. This is a bit dangerous. We answer because we think we understand, but this is not the purpose of our work. We try to intervene as little as possible. Has it already happened for an interpreter to answer?

It has [laughs].

And at that time, how did the Vietnamese and X participants react?

Well, everybody laughed.

At the beginning of their careers, when interpreters intervene, how do the Vietnamese participants react?

They are happy, yes. When they are working [during the training session], they signal to us so that we can help them. They are young, very young and they are very open. We cannot practice the skills they are learning, but sometimes, they forget something, so they ask us directly, not the trainer. They know we remember and we can easily answer. [...]

In those cases when Vietnamese participants ask you to be the expert, how does the $X$ trainer react? 
At the beginning, we don't answer directly. The first times, we ask the trainer and it is up to the trainer to answer. Then, after three or four days, the trainer simply tells us that for simple questions like that, we can answer directly. Otherwise, we always ask the trainer first. This is our task; in any case, we are not trained to be trainers. (IEE6)

In all of these types of rendition, the interpreter is clearly involved, i.e. "visible", even if unbeknownst by the interlocutors. But what about close rendition? It appears in the interviews that interpreters engage in close rendition in three cases: in straightforward technical exchanges (17), at the express demand of interlocutors who display their lack of trust towards the interpreter (18) or whose primary goal might not be an harmonious communication (19), or as a form of "voluntary disengagement" in very tensed situations (20) or on the contrary, very relaxed situations (21).

(17) And you always were told to translate as literally as possible what each side said?

Yes. As literally as possible. And in very, you know, different manners, because on this side, he was so eloquent, but on that side, he didn't say very much. (IEE2)

(18) When the interpreter does not understand something and asks a question, if there is no respect from the Vietnamese side, [then they say:] "you translate, that's it, I told you [to translate]." It is very hard. (IEE1)

(19) Again about the cultural difference, you would not ask about personal items like family but then people can insist. For example, recently, a high Vietnamese official said [to the $X$ counterpart]: pleased to meet you, are you married; and then he told me, please translate, not as a command, but he said, please, say as I am saying, and he has a reason to do that; he had a reason to tell me what he told me. After that, he would continue but it was not in a jocular mood. (IEE2)

(20) Then the boss tells me: talk to that man there and tell him what I am saying [...]. That man was not in an honorary position; he was in a fairly high position. I made sure to say: I am calling you because my boss told me so, and I am telling you exactly what he said. I said something that can be perceived as very offensive [by Vietnamese people]. I was only saying what my boss wanted me to say. But I said literally everything. (IEE2) 
(21) I will tell you a story. A Vietnamese senior official in a very relaxed conversation [during a pause] talks about something not correct, and I interpreted it [laughs]. I know he was not correct, but because he was saying it, and because people think that people with higher authority know better, I interpreted it.

Were you supposed to translate, or could you have not translated?

I wanted to translate. People were very relaxed, so if I hadn't translated, my boss on the $X$ side would have asked: what is going on, what was he saying and why did I not translate. So I translated. (IEE2)

These examples illustrate that except for the case of "straightforward technical exchanges" (that may nonetheless cover the "bulk" of interpreters' renditions), close rendition does not amount to invisibility. The "visibility" of interpreters is even more apparent when one considers how they conceive of and fulfill their roles.

\subsection{Interpreters' roles}

Just as types of rendition may vary within the same assignment and among assignments, so does the interpreters' role $(22,23)$. A strong consensus emerged among all interviewed interpreters in favour of their roles of translator (25), cultural informant (23) and cultural mediator (25), and against the role of cultural advocate (23). They were in disagreement about the role of bilingual professional $(22,23,26)$.

(22) My position as an interpreter can change depending on the task, but I am never an independent expert. (IEE3)

(23) First, translator, of course, and linguistic communicator, for sure. Cultural informant: in many cases, yes, when we need to explain whether it is culturally appropriate in Vietnam or in X. Cultural mediator: yes, sometimes we need to negotiate, for example we need to ask whether a partner accepts to answer a question [when the question is not culturally appropriate]. Cultural advocate: I think not because I only explain the situation and we respect the different cultures; if you do not want to answer, you do not answer; if you want, you do; that's it. Bilingual expert: yes, sometimes, because when we translate, in many cases we need to ask questions from our own; sometimes we are not sure we translated clearly; 
for example, sometimes we realize that a partner's answer does not correspond to the other partner's question. (IEE6)

(24) In many occasions, I would see myself as a translator, frankly. [...] we are only the go-between, a very important role but a go-between. As interpreters, we cannot make any decision; we can only have the conversation, the discussion, go through. (IEE2)

(25) The role of cultural mediator is everywhere, whatever the situation. [...] We are cultural mediators; cultural mediator, it means that we try to adapt our messages from one culture to the other. Thus, the message can pass; it must be compatible. When it passes, it means that it is compatible with the culture of the other. (IEE1)

(26) There is one role that is not possible. It is that of bilingual expert, that is when from my own initiative, I ask questions and give answers; that, I cannot do. Except for the case when I am already involved in the project, when I have a good understanding of it; then, I can allow myself to add questions to the $X$ expert's questions in order to make the situation clearer, because I also want to understand the situation better. Otherwise, I do no allow myself to ask questions. (IEE7)

The three roles most strongly acknowledged by interpreters (i.e. translator, cultural informant and cultural mediator) are those that place interpreters in the most delicate positions as intermediaries. In the most strongly rejected role of "cultural advocate", interpreters clearly take a stance for one culture against the other, and in the disagreed upon role of "bilingual professional", interpreters act in the name of their professional knowledge in a manner they consider independent from the cultures in contact. As "translators", interpreters may be engaged in exchanges where the question of cultures in contact has little relevance, but when this is not the case, they have to remain "neutral" following their own or the interlocutors' wishes, however difficult this might be. As cultural informants or cultural mediators, they act as "human bridges" between two cultures. Thus, the question of interpreters' self-perceived cultural belonging(s) warrants closer examination.

\subsection{Cultural belongings}


Although not pertaining to cultural identity stricto sensu, Jackson's Cultural Contract Theory is useful in the investigation of cultural belongings. In this theory, intercultural communication takes place within three types of contract: ready-tosign contracts in which others are expected to conform, quasi-completed contracts where there is room for partial negotiation of identities, and co-created contracts that are completely negotiable. The interviews seem to indicate that all three types of contract are encountered by interpreters.

In a work environment that implies a constant passage from one culture to another, the importance of having a strong "home base" is particularly felt. This strong "home base" is then being complemented by an openness and adaptability to other cultures (27-8); this would correspond to quasi-completed contracts. However, the "in-between" situation in which interpreters work may still feel quite uncomfortable at times (29-31). One way to opt out of this uneasiness is the adoption of ready-to-sign contracts that may take different forms. Some choose to separate their personal and professional lives along cultural lines (32). Others opt for geographical limits when it comes to deciding who needs to adapt to what (33). And still others try to evade the choice between one or the other culture by situating themselves "above" in the "higher domain of intercultural exchanges" (34), i.e. akin to the situation of co-created contracts. It is important to note that interpreters do not necessarily adopt the same attitude for each of their interpreting assignments.

(27) I am first Vietnamese, 100\% Vietnamese, yes. I can understand, I can adapt, I try to adapt; it does not mean that I can [do] it 100\%, but I try to adapt to the culture from $X$, to a mixed culture, $X$-Vietnamese and Vietnamese-X. (IEE1)

(28) If you have a cultural background that you can use as a strong basis, then you can evolve, learn things. (IEE3)

(29) From the side of [citizens of X], I felt hurt; and from the Vietnamese side, it was embarrassing [...] Little by little, I got used to ..., well, I understand the Vietnamese people and I also understand the [citizens of $\mathrm{X}$. I am still hurt when attitudes are somewhat aggressive, but well, I try to act as if I were not Vietnamese, I am only there to help partners understand each other. (IEE5) 
(30) In fact, it is sometimes very difficult with Vietnamese technicians. They often tell me: you, you are Vietnamese, you work for a foreign company, you must help Vietnamese people; we need this, we need that, we must change this, we must change that. I tell them: but this is not reasonable; I have my work; it is impossible. But I try to explain [what they want], and sometimes we find a solution to the problem. (IEE6)

(31) Sometimes, I have been in very delicate situations. I am wondering, do I work for X or for Vietnam? I am paid to work for citizens of X for X, but it is also about Vietnam. Thus, who do I really work for? I am Vietnamese, and I ask myself this question. [...] Luckily, the goals that these citizens of $X$ pursue do not violate Vietnamese rules and principles. Therefore I can help them, help them in attaining these goals. (IEE7)

(32) In daily life [at home], of course we are Vietnamese, 100\% Vietnamese. But at work, when we discuss, when we are trying to solve problems, then we do it the $\mathrm{X}$ way. (IEE6)

(33) It is to them [foreigners] to accept us and not to us to adapt to them because they are in our country; thus, they should broaden their horizons, discover our country just as when I go to their country, then I adapt, I broaden my horizons. (IEE7)

(34) I work for the $X$ side, for the government of $X$, but I am Vietnamese. Thus, I cannot say I defend the [citizens of $X$ ], $X$ against Vietnam. This is very difficult. I would be an advocate for a win-win [situation], for some compromise rather than for one side. (IEE2)

The three different types of cultural contract (i.e. ready-to-sign, quasi-completed, co-created) have a different impact on the interpreters' approach to their tasks and ultimately on the interpreter-mediated communication. They depend on the understanding interpreters have of, primarily, their cultural belongings, and secondarily, of the purpose of their work in the general socio-cultural context.

\section{Conclusion}

The study presented above is exploratory. It gave a very general picture of highlevel Vietnamese interpreters working in Vietnam in French or English. It appeared that this picture is not fundamentally different from the one described 
by Angelelli (a) in her study of community interpreters working with immigrants in an American healthcare centre. The stakes however differ: uniquely national in community settings vs. national and international in the case of Vietnamese interpreters in Vietnam. Thus, to the question of "individual pride" (i.e. self-perception as an individual) is added that of "national pride" (i.e. self-perception as a member of a national society) in a more significant manner; in complicating the situation, this heightens the crucial need to pay more attention to interpreters' identities. Training in intercultural communication for interpreters has already been advocated and it is certainly supported here. However, it would seem appropriate to add systematic training that would help interpreters discover who they are, who they want to be, what role they want to play in their interlocutors' exchanges, and how they want these exchanges to have an impact on lives at the personal, local, national and international levels, because each of these questions has an impact on the type and quality of interpretation. Concurrently, more research needs to be conducted, for example, on the impact of interpreters' chosen cultural belonging(s) on interpretermediated events, and more concretely on the personal, contextual and cultural (group) characteristics that will have an impact on the interpreter's choice (a) to step from a cultural mediator's role into a bilingual professional's role, (b) to voluntarily "disengage" from an interpreted communicative event, or (c) to differentiate between their cultural identities along the lines of personal / professional, here / there, national cultures / intercultural sphere.

The purpose of this paper has been to submit that the progressive disappearance of the interpreters' invisibility myth must be accompanied by an increased attention paid to the "person" of interpreters. It is recognised that most interpreters may not suffer from big pangs of conscience about their cultural belongings and conception of the overall value of their work; nonetheless, a better awareness of these issues would enable a better control of the situation, and thus would certainly help improve the quality of interpreter-mediated events and result in enhanced intercultural relations. Indeed, if experienced highlevel interpreters qualify situations in which they may find themselves from time to time as "very delicate", it is reasonable to think that the issue is even more sensitive for interpreters at early stages in their careers.

Note: The authors most sincerely thank the interpreters who participated in this study for their trust and generosity. They also gratefully acknowledge the help of 
TranscUlturAl, vol.1, 2(2009), 93-116

http://ejournals.library.ualberta.ca/index.php/TC

Ksenia Svechnikova, graduate student at the University of Alberta, for the literature review. 
TranscUlturAl, vol.1, 2(2009), 93-116

http://ejournals.library.ualberta.ca/index.php/TC

\section{References}

Alexieva, Bistra. "A Typology of Interpreter-Mediated Events." The Translator: Studies in intercultural communication 3.2 (1997): 153-74.

Angelelli, Claudia V. (a) Medical Interpreting and Cross-Cultural Communication. Cambridge: Cambridge University Press, 2004.

---. (b) Revisiting the Interpreter's Role. A Study of Conference, Court, and Medical Interpreters in Canada, Mexico, and the United States. Amsterdam, Philadelphia: John Benjamins, 2004.

Bolden, G. "Towards Understanding Practices of Medical Interpreting: Interpreters' Involvement in History Taking." Discourse Studies 2.4 (2000): 387-419.

Brunette, Louise, et al., eds. The Critical Link 3: Interpreters in the Community. Amsterdam, Philadelphia: John Benjamins, 2001.

Hecht, Michael L., Ronald L. Jackson, and Sidney A. Ribeau. African-American Communication: Exploring Identity and Culture. 2nd ed. Mahwah (NJ): Lawrence Erlbaum, 2003.

Jackson, R.L., II. "Cultural Contracts Theory: Towards an Understanding of Identity Negotiation." Communication Quaterly 50.3 \& 4 (2002): 359-67.

Jalbert, M. "Travailler Avec Un Interprète En Consultation Psychiatrique." PRISME 8.3 (1998): 94-111.

Kaufman, Francine. "L'interprète Serviteur De Plusieurs Maîtres?" Übersetzen Translating - Traduire. Towards a "Social Turn"? Ed. Michaela Wolf. Münster, Hamburg, Berlin, Wien, London: LIT - Verlag, 2006. 187-97.

Leanza, Yvan. "Roles of Community Interpreters in Pediatrics as Seen by Interpreters, Physicians and Researchers." Healthcare Interpreting. Discourse and Interaction. Eds. Franz Pöchhacker and Miriam Shlesinger. Amsterdam, Philadelphia: John Benjamins, 2007. 11-34.

Metzger, Melanie. Sign Language Interpreting: Deconstructing the Myth of Neutrality. Washington (DC): Gallaudet University Press, 1999.

Navarro-Montesdeoca, Guillermo R. "Interpreting at an Immigration Detention Center in Las Palmas De Gran Canaria." Sociocultural Aspects of Translating and Interpreting. Eds. Anthony Pym, Miriam Shlesinger and Zuzana Jettmarovà. Amsterdam, Philadelphia: John Benjamins, 2006. 163-71. Pöllabauer, Sonja. "'Translation Culture" in Interpreted Asylum Hearings." Sociocultural Aspects of Translating and Interpreting. Eds. Anthony Pym, Miriam Shlesinger and Zuzana Jettmarovà. Amsterdam, Philadelphia: John Benjamins, 2006. 151-62. 
Pym, Anthony. "On the Social and the Cultural in Translation Studies." Sociocultural Aspects of Translating and Interpreting. Eds. Anthony Pym, Miriam Shlesinger and Zuzana Jettmarovà. Amsterdam, Philadelphia: John Benjamins, 2006. 1-25.

Roberts, Roda P., et al., eds. The Critical Link 2: Interpreters in the Community. Amsterdam, Philadelphia: John Benjamins, 1999.

Roy, Cynthia B. Interpreting as a Discourse Process. New York, Oxford: Oxford University Press, 2000.

Rudvin, Mete. "Negotiating Linguistic and Cultural Identities in InterpreterMediated Communication for Public Health Services." Sociocultural Aspects of Translating and Interpreting. Eds. Anthony Pym, Miriam Shlesinger and Zuzana Jettmarovà. Amsterdam, Philadelphia: John Benjamins, 2006. 173-90.

Shannon, Claude E., and Warren Weaver, eds. The Mathematical Theory of Communication. Urbana (IL): University of Illinois Press, 1949.

Wadensjö, Cecilia. Interpreting as Interaction. London, New York: Longman, 1998. 


\section{Appendix A: Interview guideline}

The purpose of this interview is to help us better understand (and not evaluate) interpreters' interactions with Vietnamese and Anglophone/Francophone partners. Our general goal is to find out ways that could help Vietnamese interpreters perform their crucial and difficult work.

\section{Specific questions}

\section{Appropriateness}

Can you tell us about cases when Anglophone/Francophone or Vietnamese partners particularly behaved in an appropriate manner? In an inappropriate manner? How did you react in such cases?

\section{Efficiency}

Can you tell us about cases when Anglophone or Vietnamese partners particularly behaved in an efficient manner? In an inefficient manner? How did you react in such cases?

\section{Pleasantness}

Can you tell us about cases when Anglophone/Francophone and/or Vietnamese partners seemed genuinely pleased with what was going on? When they appeared disconcerted / annoyed / unhappy with what was going on? How did you react in such cases?

\section{Cultural knowledge}

Can you tell us about cases when Anglophone/Francophone partners displayed their lack of knowledge about Vietnamese society and culture? When Vietnamese partners showed they did not understand / they were surprised (in any way) by their Anglophone/Francophone partners? How did you react in such cases?

\section{General questions}


5. How do you personally evaluate the manner in which Anglophone/Francophone and Vietnamese partners interact with each other, and how you do your own interpretation work?

6. Are the cases you have just told us about representative of your work as an interpreter in general? If no, how do they differ from it?

7. How do you evaluate your work conditions as an interpreter (in terms of language difficulties, context, clients, etc.)?

\section{Synthesis: Interpreter's role}

8. Can you tell us of cases when you had the impression that

a. one or both parties trusted you to the point of letting you know of their goals and letting you take initiatives so that they would reach their goals?

b. one or both parties kept information for themselves that might have been useful for you in your work?

$\Rightarrow$ How do you explain such situations?

What was the outcome of these interactions?

9. In your interpreting assignments, would you say

a. you are working for the party that hired you (i.e. pays your salary)?

b. you are working for both parties?

c. you are working as an independent professional?

d. you are working in any other capacity? Which one?

$\Rightarrow$ Does your position change depending on your assignment? How?

10. Do you see your role as one of

a. translator: you facilitate the linguistic communication process and try not interfere with what the parties say;

b. cultural informant: you help one party better understand the other by using your knowledge of cultural norms and values;

c. cultural broker or cultural mediator: you are a cultural informant and also a negotiator between two conflicting value systems;

d. advocate: in a value-conflict situation, you choose to defend one party against the other;

e. bilingual professional: on your own, you take the initiative to ask questions to one party and then reports to the other party. 
TranscUlturAl, vol.1, 2(2009), 93-116

http://ejournals.library.ualberta.ca/index.php/TC

11. How would you define yourself culturally? Has your work had an impact, and how, on your cultural identity?

12. Is there any question we should have asked you but did not? Do you have any other information to add to what you have already told us? 